\title{
Association of pro/anti-inflammatory cytokine gene variants in renal transplant patients with allograft outcome and cyclosporine immunosuppressant levels
}

\author{
Parmeet Kaur Manchanda \\ Anant Kumar \\ Raj K Sharma \\ Himanshu Goel \\ Rama Devi Mittal \\ Department of Urology and Renal \\ Transplantation, Sanjay Gandhi \\ Post Graduate Institute of Medical \\ Sciences, Raebareli Road, Lucknow \\ 2260 I4, Uttar Pradesh, India
}

\begin{abstract}
T-helper (Th) type 1/Th2 cytokines are key mediators in induction/effecter phases of all immune and inflammatory responses playing role in acute/chronic renal allograft rejection. Association studies lead to identification of patient risk profiles enabling individualization of level of immunosuppressions. We investigated the association of allograft rejection with interleukin-2 (IL-2), IL-4, IL-6, tumor necrosis factor- $\alpha$ (TNF- $\alpha$ ) -308 , transforming growth factor- $\beta$ (TGF- $\beta$ ) (C-del, codon 10 and 25) gene variants in 184 renal transplant recipients and 180 controls. These cytokine genotypes were also evaluated with cyclosporine levels (C2) at one month in 135 stable recipients. High producing genotypes B1B1 of IL- 4 and AA of TNF- $\alpha-308$ showed significant association with rejection of allograft. The dose-adjusted $\mathrm{C} 2$ levels were significantly lower in patients with the high producing genotype T/T of IL-2 and heterozygous G/C of TGF- $\beta$ codon 25 ( $P=0.012$ and 0.010 , respectively). Haplotype frequencies were comparable in subjects for TGF- $\beta$ codon-10 and 25 . Combined inter-gene interaction showed high risk for rejection in recipients with high producing genotype B1B1 of IL-4 and AA of TNF- $\alpha$ and high TNF- $\alpha$ (AA) with low TGF- $\beta$ (CC or Pro/Pro). In conclusion, association of IL-4 VNTR and TNF- $\alpha-308$ suggested the involvement of these cytokines contributing to pathogenesis of allograft rejection. Recipients with TT genotype of IL-2 and GC of TGF- $\beta$ codon 25 having low $\mathrm{C} 2$ levels may require higher cyclosporine dosage. Combined analysis of gene-gene interaction demonstrated synergistic effect of cytokines increasing risk for rejection. Thus, this information may help in pre-assessment of allograft outcome and to optimize cyclosporine therapy in post-transplant patients.
\end{abstract}

Keywords: cytokines, renal transplant, polymorphism, ARMS-PCR, PCR-RFLP, cyclosporine

\section{Introduction}

Renal transplantation is a better choice for treatment of end stage renal disease. However, after kidney transplantation patients need permanent immunosuppressive medication to prevent graft rejection and loss of graft. The mechanism of all current immunosuppressive drugs target $\mathrm{T}$ cell activation, cytokine production and clonal expansion. Cyclosporine and tacrolimus inhibits the phosphatase activity of calcineurin, thereby suppressing the production of Interleukin-2 (IL-2) and other cytokines (Myers et al 1991). The use of immunosuppressive drugs requires a fine balance between adequate immunosuppressant to prevent rejection and excessive dosage leading to toxicity.

Genetic variations in genes encoding different T-helper (Th) type 1 and Th2 cytokines, chemokines and their receptors, growth factors, molecules of the renin-angiotensin system, enzymes of the homocysteine pathway, and proteins acting as substrates of immunosuppressive drugs influence impact on success of engraftment 
and highlight the concept of genetic predisposition to allograft rejection (Khan et al 2006). Several studies on functional variants caused by single nucleotide polymorphisms (SNPs) in genes encoding drug metabolizing enzymes, transporters, ion channels and drug receptors have been known to be associated with inter-individual, interethnic variation in drug response and play role in influencing the efficacy and toxicity of medications (Koo and Lee 2006). It has been suggested that cytokine genotyping may play a predictive role in identifying individuals who are at higher risk of acute rejection by individualizing their immunosuppression levels (Loucaidou et al 2005).

As polymorphisms segregate independently any one individual might respond with a pattern of quite different cytokine expression from another individual. Cytokine interactions are complex and it is unlikely that a single allelic variant results in either graft rejection or induction of allograft tolerance (Mas et al 2007). Heritable cytokine polymorphisms have been shown to account for differences in allograft survival. For instance, recipients of renal allograft whose genotypes predicted high tumor necrosis factor- $\alpha$ (TNF- $\alpha$ ) and IL-10 production were more likely to undergo an acute rejection episode than individuals with genotypes predicting low TNF- $\alpha$ and IL-10 production (Sankaran et al 1999). High IL-6 producing individuals have previously been shown to be at heightened risk for acute rejection (Marshall et al 2000). Further, Cox and colleagues (2001) observed an increase in IL-2 and IL-6 production associated with rejection events. Polymorphisms in codon 10 and codon 25 of transforming growth factor- $\beta$ (TGF- $\beta$ ) gene result in high producer phenotype and have been associated with chronic transplant rejection (Hutchinson et al 1999). Poole and colleagues (2001) reported absence of IL-4 T allele in both recipient and donor, ie, recipient low producer/donor low producer, was significantly increased in rejection group. We thus utilized this information in evaluating the association of IL-2, IL-4, IL-6, TNF- $\alpha$, and TGF-B cytokine gene polymorphisms with the risk of allograft rejection. We further assessed the possibility of these gene variants associations with cyclosporine level in stable renal transplant recipients from the North Indian population.

\section{Materials and methods}

\section{Subjects}

We studied one hundred eighty-four recipients of renal transplants from a live related donor at our tertiary care hospital over a period of three years (2004-2006). Informed consent was obtained from recipients and controls participating in this study. Approval of this study was obtained from local Ethical Committee of Sanjay Gandhi PGIMS, Lucknow. Transplant patients who were HbsAg and HCV positive were excluded from study to rule out the possible cause of rejection. Patients were typed for human leukocyte antigen (HLA) A, B and DR, DQ antigen. Controls ( $n=180)$ included healthy individuals visiting the hospital and staff/employees with no history of hypertension, diabetes, renal failure, vascular diseases, stroke/cardiomyopathy. Both patients and control groups had similar ethnicity.

\section{Clinical data}

The demographic and clinical details have been described in Table 1. Patients were followed for at least 2 years after transplantation. There were 34 patients (age range 19-55, M:F 28:6) with clinical and biopsy proven rejection episode (RE). All patients had single rejection episode except two, who experienced rejection more than once and one patient out of this had gone for re-transplantation. Clinical rejection was identified as an increase in creatinine levels in absence of infection, obstruction or evidence of drug toxicity, associated with a fall to within $10 \%$ of baseline creatinine level after treatment. All biopsies were reviewed by a renal pathologist, and the Banff 93 working classification criteria were used in the histological classification of biopsies (Racusen et al 1999). Fifteen patients (age range 19-53, M: F 15:0) experienced delayed graft functioning (DGF) who required dialysis within the first 7-10 days of post transplantation and 135 had stable graft functioning (SGF) (age range 17-64, M:F 118:17) without episode of rejection/any infection and obstruction except one patient who had a history of cytomegalovirus (CMV) infection.

Patient's immunosuppressive therapy consisted of cyclosporine, azathioprine and corticosteriod. Daily doses of CsA were adjusted according to C-2 levels. For all patients the initial dosage of cyclosporine was $8 \mathrm{mg} / \mathrm{kg} / \mathrm{d}$ to achieve $\mathrm{C} 2$ level of $1.8 \mu \mathrm{g} / \mathrm{ml}$ which was subsequently reduced to 1.6 , $1.4,1.2,1.0$, and 0.8 after $1,3,6$, and 12 months. Intravenous methylprednisolone was given at a standard dosage regimen of $500 \mathrm{mg}$ of at the time of surgery, $125 \mathrm{mg}$ intravenously the following day and then $20 \mathrm{mg}$ of prednislolone daily. Oral prednisolone was then tapered to $10 \mathrm{mg}$ daily at 3 mo transplantation. There were only eight patients receiving tacrolimus and were not included in the study due to low number.

\section{Cyclosporine determination}

Cyclosporine $\left(\mathrm{C}_{2}\right)$ values in whole blood were assayed with Emit (Enzyme multiplied immunologic technique) 2000 
Table I Demographic and clinical details in study population

\begin{tabular}{|c|c|c|c|c|c|}
\hline Characteristics & $\operatorname{RE}(\mathbf{N}=34)$ & DGF $(N=15)$ & SGF $(N=135)$ & Controls $(\mathbf{N}=180)$ & $\begin{array}{l}\text { P-value (RE and } \\
\text { DGF vs SGF) }\end{array}$ \\
\hline Age at time of Tx (yrs) & $19-55(34.63 \pm 9.4)$ & $19-53(35.5 \pm 10.1)$ & $17-64(36.10 \pm 10.3)$ & $15-6734.96 \pm 11.3$ & NS \\
\hline${ }^{*}$ Gender (M:F) & $28: 6$ & $15: 0$ & $118: 17$ & $102: 78$ & NS \\
\hline \multicolumn{6}{|l|}{ "Donor age (No) } \\
\hline$>50$ & 10 & 3 & 29 & - & NS \\
\hline$<50$ & 24 & 12 & 106 & & \\
\hline $\mathrm{CGN}^{\mathrm{a}}(\mathrm{n}=154)$ & 26 & 12 & 116 & - & \\
\hline Others $^{b}(n=30)$ & 8 & 3 & 19 & - & \\
\hline "Body weight (kg) & $36-70(53.0 \pm 8.5)$ & $33-68(54.3 \pm 7.2)$ & $30-80(52.9 \pm 8.8)$ & $45-79(55.6 \pm 7.9)$ & NS \\
\hline $\begin{array}{l}\text { "Cyclosporine dosage, } \\
\text { I Month (mg/d) }\end{array}$ & $275-600(367.4 \pm 71.5)$ & $273-600(358 \pm 69.3)$ & $250-700(386.7 \pm 83.5)$ & - & NS \\
\hline $\begin{array}{l}\text { *Cyclosporine dosage, } \\
\text { I2 Month (mg/d) }\end{array}$ & $100-175(120.8 \pm 20.9)$ & $100-175(112 \pm 20.1)$ & $50-175(111.5 \pm 23.0)$ & - & NS \\
\hline${ }^{*} \mathrm{C} 2$ conc $(\mu \mathrm{g} / \mathrm{ml}), \mathrm{I}$ mo & $1.64 \pm 0.12$ & $1.61 \pm 0.11$ & $1.60 \pm 0.13$ & - & 0.032 (RE vs SGF) \\
\hline
\end{tabular}

Notes: ${ }^{\mathrm{C} C h r o n i c}$ glomerulonephritis; ${ }^{\mathrm{H} H y p e r t e n s i o n ~(12), ~ d i a b e t e s ~ m e l l i t u s ~(15) ~ a n d ~ p o l y c y s t i c ~ k i d n e y ~ d i s e a s e ~(2) ~ a n d ~ A l p o r t ~ s y n d r o m e ~(I) ; ~}{ }^{\prime}$ Mean \pm SD; P $>0.05$ (Multinomial logistic analysis); NS, nonsignificant.

(Dade Behring Inc, Deerfield, IL). Peripheral blood samples were collected after 2 hours in morning following oral administration of cyclosporine post transplantation. Patient's weight and daily dose of cyclosporine (in milligrams) were also recorded.

\section{DNA extraction and cytokine genotyping}

Genomic DNA was extracted from peripheral blood samples collected from transplant recipients and healthy volunteers by salting out method (Miller et al 1988). SNPs in the cytokine genes were genotyped by polymerase chain reaction-restriction fragment length polymorphism (PCR-RFLP) in IL-2, TGF- $\beta$ (C-del), and TNF- $\alpha-308$, variable number tandem repeats (VNTR) analysis in IL-4 and amplification refractory mutatory systems (ARMS)-PCR in IL-6 and TGF- $\beta$ (codon 10 and 25) as reported previously (Pociot et al 1998; Perrey et al 1999; Cox et al 2001; Tsai et al 2001; Gyan et al 2004; Tan et al 2005).

To improve the genotyping quality and substantiation, $30 \%$ of samples were re-genotyped by other laboratory personnel and results were reproducible with no discrepancy recorded in genotyping. Genotyping of $10 \%$ of samples were confirmed by DNA sequencing.

\section{Data analysis}

Statistical analysis was performed using the $\chi^{2}$ test to compare the genotype frequency distribution in patients and controls with SPSS software (version 11.5; SPSS Inc., Chicago, IL) using Pearson chi-square or Fisher's exact test.
Multinomial logistic analysis was performed to investigate the impact of multiple factors like age, gender and body weight with graft outcome. The mean concentration of cyclosporin and dosage and numerical values was tested by the Student $t$-test or ANOVA test. Univariate analysis with Bonferroni correction was performed to see the differences between groups SGF with RE and SGF with DGF. Odds ratio (OR) at $95 \%$ confidence intervals $(\mathrm{CI})$ was also determined to describe the strength of association using binary logistic regression model (BLRM). For nonparametric data of cyclosporine concentration among different genotypic groups Kruskal-Wallis test was employed. To examine whether genotype frequencies were in Hardy-Weinberg equilibrium, Goodness of fit $\chi^{2}$ tests was used. Haplotype frequencies and linkage disequilibrium between each pair of TGF- $\beta$ (codon-10 and 25) was determined by Arlequin (version 2.0). To analyze the haplotypes and combination of genotypes we did logistic regression analysis by keeping case-control as dependent variable and haplotype/genotypic combination as factors. $P$ value $<0.05$ was considered statistically significant.

\section{Results}

\section{Association of subject characteristics}

Multinomial logistic analysis was performed between RE vs SGF and DGF vs SGF to investigate the impact of set of predictor variables like recipient and donor age, gender and body weight on the outcome of allograft (ie, rejection and delayed 
graft functioning). The mean concentration of cyclosporin dosage and $\mathrm{C} 2$ levels on the rejection of allograft was tested by the ANOVA test. Significant association was seen for C2 levels at 1 month between RE and SGF ( $p=0.032)$. However, no significant difference was observed for any of the other factors $(\mathrm{p}>0.05)$ (Table 1$)$.

\section{Association of allograft function with combined effect of degree of HLA mismatches and genotypes}

Evaluation was done for HLA DR, DQ mismatches (MM) in combination with genotypes of all the cytokine genes studied in RE and SGF recipients. We excluded the DGF group as none of the cytokine genes showed any significant association or risk for rejection and also the number was too low for combined regression analysis. Recipients were divided into two groups: 0-2 MM and 3-4 MM and their interaction with genotypes was evaluated with risk of rejection using binary logistic regression analysis by taking SGF and RE as dependent variable and number of MM and genotypes as categorical. Binary logistic regression analysis of combined effect of number of DR and DQ mismatches with different genotypes showed no significant risk for the rejection of allograft (Table 2).

Frequency of IL-2, IL-4, IL-6, TNF- $\alpha-308$ G/A and TGF- $\beta$ (7|3-8delC, codon 10 and 25 ) variants in renal transplant recipients

Genotype frequency distributions are represented in Table 3. The genotype frequency distributions did not deviate from Hardy-Weinberg equilibrium except for TGF- $\beta$ codon 25 . Frequency distribution in TGF- $\beta$ codon 25 genotypes Arg/Arg (66.7\%), Arg/Pro (23.3\%) and Pro/Pro (10\%) in our population was comparable to a study of McDaniel and colleagues (2003) and Skorpil and colleagues (2007) in African-Americans and Italian populations, respectively. Gendzekhadze and colleagues (2006) and Alakulppi and colleagues (2004) reported 0\% frequency in mutant Pro/Pro genotype while Park and colleagues (2004) showed $0 \%$ in both mutant as well as heterozygous genotypes and $100 \%$ in wild homozygous (Arg/Arg), signifying that this gene may have varied frequencies among different populations. Duplicate quality control DNA samples showed $>95 \%$ agreement for all genotyping. Further laboratory personnel were blinded to case-control status and to achieve $>95 \%$ accuracy in genotyping. The genotype frequencies of total number of patients were compared with controls for the cytokine genes studied to see whether any of these cytokines were
Table 2 Binary logistic regression analysis of combined effect between SGF and RE of number of mismatches with different genotypes predicting the risk of rejection

\begin{tabular}{|c|c|c|}
\hline Variable (reference group) & P-value & OR, 95\% Cl \\
\hline \multicolumn{3}{|l|}{$\begin{array}{l}\text { IL-2 (TT)-HLA DR, DQ MM } \\
(0-2 \text { MM) }\end{array}$} \\
\hline GG & 0.284 & $0.3|3,0.03-2.6|$ \\
\hline TG & 0.475 & $0.705,0.27-1.84$ \\
\hline \multicolumn{3}{|l|}{$\begin{array}{l}\text { II-4 (B2B2)-HLA DR, DQ MM } \\
(0-2 \mathrm{MM})\end{array}$} \\
\hline $\mathrm{BIBI}$ & 0.999 & - \\
\hline BIB2 & $0.77 \mid$ & $0.839,0.25-2.73$ \\
\hline \multicolumn{3}{|l|}{$\begin{array}{l}\text { IL-6 (CC)-HLA DR, DQ MM } \\
(0-2 \text { MM) }\end{array}$} \\
\hline GG & 0.346 & $0.658,0.27-1.57$ \\
\hline GC & 0.803 & $1.205,0.27-5.23$ \\
\hline \multicolumn{3}{|l|}{$\begin{array}{l}\text { TNF- } \alpha 308 \text { (GG)-HLA DR, } \\
\text { DQ MM (0-2 MM) }\end{array}$} \\
\hline AA & 0.946 & $0.959,0.28-3.23$ \\
\hline GA & 0.283 & $0.548,0.18-1.64$ \\
\hline \multicolumn{3}{|l|}{$\begin{array}{l}\text { TGF- } \beta \text { Cod-I0 (TT)-HLA DR, } \\
\text { DQ MM (0-2 MM) }\end{array}$} \\
\hline $\mathrm{CC}$ & 0.745 & $1.304,0.26-6.48$ \\
\hline $\mathrm{TC}$ & 0.165 & $0.522,0.20-1.30$ \\
\hline \multicolumn{3}{|l|}{ TGF- $\beta$ Cod-25 (GG)-HLA } \\
\hline \multicolumn{3}{|l|}{ DR, DQ MM (0-2 MM) } \\
\hline $\mathrm{CC}$ & 0.806 & $0.812,0.15-4.29$ \\
\hline GC & 0.175 & $0.433,0.12-1.45$ \\
\hline $\begin{array}{l}\text { TGF- } \beta \text { C-del (CC/CC)-HLA } \\
\text { DR, DQ MM (0-2 MM) }\end{array}$ & & \\
\hline $\mathrm{C} / \mathrm{CC}$ & 0.222 & $0.379,0.08-1.79$ \\
\hline HLA DR, DQ MM (0-2 MM) & 0.363 & $0.682,0.29-1.55$ \\
\hline
\end{tabular}

associated with the end stage renal disease in patients. Significant difference in the genotypic frequencies between patients and controls were observed for IL-4, TNF- $\alpha-308$ and TGF- $\beta$ codon 10 ( $\mathrm{P}<0.001$, Pearson Chi-square test).

The patients were categorized into subgroups, RE and DGF and were compared with SGF to study the allograft impact pattern and the risk for rejection. Univariate analysis was performed and the $\mathrm{p}$-values were adjusted by Bonferroni correction (Table 4). Results revealed significant differences between SGF and RE in IL-4 and TNF- $\alpha-308$ gene $(p=0.027$ and 0.012$)$. The frequency of high producing genotype B1B1 was $11.8 \%$ in RE, $2.2 \%$ in SGF and $0.5 \%$ in controls showing $>6$-fold high risk in RE (OR, 6.815; 95\%CI, 1.40-33.08; RE vs SGF; OR was calculated using Binary logistic regression analysis). Frequency of high producing genotype AA of TNF- $\alpha-308$ 
Table 3 Genotype frequencies of IL-2 -330 T/G, IL-4VNTR, intron 3, IL-6 - I74 G/C,TNF- $\alpha-308$ G/A and TGF-B [7I3-8delC, codon $10 \mathrm{~T} / \mathrm{C}$ (Leu/Pro) and $25 \mathrm{G} / \mathrm{C}$ (Arg/Pro)] gene in transplant recipients (RE, DGF, SGF) and controls

\begin{tabular}{|c|c|c|c|c|c|c|}
\hline Gene & Genotype & $\begin{array}{l}\text { Controls } \\
\text { (I80); (\%) }\end{array}$ & $\begin{array}{l}\text { Total recipients } \\
\text { (I 84); (\%) }\end{array}$ & $\begin{array}{l}\text { RE } \\
\text { (34); (\%) }\end{array}$ & $\begin{array}{l}\text { DGF } \\
\text { (15); (\%) }\end{array}$ & $\begin{array}{l}\text { SGF } \\
(135) ;(\%)\end{array}$ \\
\hline \multirow[t]{3}{*}{ IL-2 -330 } & TT (HP) & $54(30.0)$ & $69(37.5)$ & $16(47.1)$ & $4(26.7)$ & $49(36.3)$ \\
\hline & TG (Inm) & $100(55.6)$ & $83(45.1)$ & $12(35.3)$ & $9(60.0)$ & $62(45.9)$ \\
\hline & GG (LP) & $26(14.4)$ & $32(17.4)$ & $6(17.6)$ & $2(13.3)$ & $24(17.8)$ \\
\hline \multirow[t]{3}{*}{ IL-4 VNTR, Intron 3} & $\mathrm{BIBI}(\mathrm{HP})$ & I (0.5) & $8(4.3)$ & $4(11.8)$ & I (6.7) & $3(2.2)$ \\
\hline & BIB2 (Het) & $95(52.8)$ & $60(32.6)$ & $12(35.3)$ & $8(53.3)$ & $40(29.6)$ \\
\hline & B2B2 (LP) & $84(46.7)$ & $116(63.1)$ & I8 (52.9) & $6(40.0)$ & $92(68.2)$ \\
\hline \multirow[t]{3}{*}{ IL-6 - I74 } & GG (HP) & $109(68.5)$ & | 32 (7|.7) & $26(76.4)$ & $12(80.0)$ & $94(69.63)$ \\
\hline & GC & $53(24)$ & $23(12.5)$ & $4(11.8)$ & I (6.7) & $18(13.33)$ \\
\hline & CC (LP) & I8 (7.5) & $29(15.8)$ & $4(11.8)$ & $2(13.3)$ & $23(17.04)$ \\
\hline \multirow[t]{3}{*}{ TNF- $\alpha(-308)$} & GG & $118(65.6)$ & $45(24.4)$ & $2(5.9)$ & $4(26.7)$ & $39(28.9)$ \\
\hline & GA & $47(26.1)$ & 84 (45.7) & $17(50.0)$ & $8(53.3)$ & $59(43.7)$ \\
\hline & $\mathrm{AA}(\mathrm{HP})$ & $15(8.3)$ & 55 (29.9) & I5 (44.I) & $3(20.0)$ & 37 (27.4) \\
\hline \multirow[t]{2}{*}{ "TGF-B (C-del) } & $\mathrm{C} / \mathrm{CC}$ & $27(I 5.0)$ & $28(15.2)$ & $9(26.5)$ & $3(20.0)$ & $16(11.9)$ \\
\hline & $\mathrm{CC} / \mathrm{CC}(\mathrm{HP})$ & $153(85.0)$ & $156(84.8)$ & $25(73.5)$ & $12(80.0)$ & $119(88.1)$ \\
\hline \multirow[t]{3}{*}{ TGF-B (Codon- I0) } & Leu/Leu (HP) & $65(36.1)$ & $29(15.8)$ & $2(5.9)$ & $3(20.0)$ & $24(17.8)$ \\
\hline & Leu/Pro & $92(5 \mathrm{I} .1)$ & $109(59.2)$ & $19(55.9)$ & $9(60.0$ & $81(60.0)$ \\
\hline & Pro/Pro & $23(12.8)$ & $46(25.0)$ & $13(38.2)$ & $3(20.0)$ & $30(22.0)$ \\
\hline \multirow[t]{3}{*}{ TGF-B (Codon-25) } & Arg/Arg (HP) & $120(66.7)$ & $116(63.0)$ & $22(64.7)$ & $10(66.7)$ & $84(62.2)$ \\
\hline & Arg/Pro & $42(23.3)$ & $36(19.6)$ & $6(17.65)$ & $2(13.3)$ & $28(20.8)$ \\
\hline & Pro/Pro & $18(10.0)$ & $32(17.4)$ & $6(17.65)$ & $3(20.0)$ & $23(17.0)$ \\
\hline
\end{tabular}

Notes: P-values are for "total recipients vs Controls; IL-2: 0.I36; IL-4: <0.00I; IL-6: <0.00I; TNF- $\alpha:<0.00$ I;TGF- $\beta$ C-del: ${ }^{0} 0.535$; TGF- $\beta$ I0: $<0.00$ I; TGF- $\beta$ 25: 0.12 I; ${ }^{*}$ Pearson Chi-square; ${ }^{*}$ Fischer exact test.

was highest among RE as compared to SGF and controls (44.1\%, 27.4\% and 8.3\%; $\mathrm{p}=0.012$, RE vs SGF). The AA genotype showed $>7$-fold higher risk for rejection (OR, 7.905; 95\%CI, 1.69-36.96; $p=0.009)$. TGF- $\beta$ C-del showed a marginal significance $(p=0.054)$ and the frequency of low producing genotype $\mathrm{C} / \mathrm{CC}$ of TGF- $\beta$ was highest among $\mathrm{RE}$ showing 2.6-fold (OR, 2.677; 95\%CI, 1.06-6.74; $\mathrm{p}=0.037$ ). Further, frequency of low producing genotype pro/pro (CC) of TGF- $\beta$ codon 10 was higher in RE (38.2\%) as compared to SGF (20.0\%) and showed 5-fold risk for rejection (OR, 5.200; 95\%CI, 1.06-25.30; $\mathrm{p}=0.041$ ). No significant difference was observed between patients vs controls and RE vs SGF for IL-2, IL-6, and TGF- $\beta$ codon 25.

\section{Cytokine gene polymorphism and risk of delayed graft function}

Although the number of DGF patients was quite low for analysis, however, analysis was done to see any risk of cytokine genes polymorphism associated with delayed graft functioning. DGF group was compared to SGF. The results revealed no significant association for any of the cytokines with the risk for DGF as compared to SGF.

\section{Effects of cytokine SNPs on cyclosporine dose requirement}

We examined the relationship between each SNP of the cytokine genes and cyclosporine pharmacokinetic parameter $\mathrm{C} 2$ level $\mu \mathrm{g} / \mathrm{ml}$ for 1 month in 135 stable renal transplant patients (Table 5). A Maximum variation for adjustment for dose occurs as during first month of post-transplantation. This was a case only study and cyclosporine levels of the patients with their genotype groups were compared using Kruskal-Wallis test. Of 7 cytokine SNPs tested, two cytokines IL-2 and TGF- $\beta$ codon 25 SNP were significantly associated with the dose-adjusted $\mathrm{C} 2$ level ( $P=0.012$, and 0.010 , respectively). The $\mathrm{C} 2$ levels were significantly lower in patients with the high producing genotype T/T of IL- 2 and heterozygous G/C of TGF- $\beta$ codon 25 .

\section{Linkage disequilibrium and haplotype distribution}

The two sites codon 10 and 25 of TGF- $\beta$ have been found to be in linkage disequilibrium therefore we constructed haplotypes between these two sites to see their contribution to risk of disease/rejection using Arlequin software. The reconstructed haplotypes of contols, recipients, RE and SGF were compared and risk was estimated by binary logistic 
Table 4 Adjusted P-values of IL-2 -330 T/G, IL-4 VNTR, intron 3, IL-6 - I74 G/C,TNF- $\alpha$-308 G/A andTGF-B [7/3-8delC, codon I0 T/C (Leu/Pro) and 25 G/C (Arg/Pro)] gene for multiple comparisons between SGF-RE and SGF-DGF

\begin{tabular}{|c|c|c|c|}
\hline Gene & Genotype & $\begin{array}{l}\text { P-value } \\
\text { (SGF vs RE) }\end{array}$ & $\begin{array}{l}\text { P-value } \\
\text { (SGF vs DGF) }\end{array}$ \\
\hline \multirow[t]{3}{*}{ IL-2 -330 } & TT & (Ref) & (Ref) \\
\hline & TG & 0.665 & 1.000 \\
\hline & GG & 1.000 & 1.000 \\
\hline \multirow[t]{3}{*}{ IL-4 VNTR, Intron 3} & $\mathrm{BIBI}$ & 0.027 & 0.649 \\
\hline & BIB2 & 0.102 & 0.139 \\
\hline & B2B2 & (Ref) & (Ref) \\
\hline \multirow[t]{3}{*}{ IL-6 - I74 } & GG & 1.000 & 1.000 \\
\hline & GC & 1.000 & 1.000 \\
\hline & $\mathrm{CC}$ & (Ref) & (Ref) \\
\hline \multirow[t]{3}{*}{ TNF- $\alpha(-308)$} & GG & (Ref) & (Ref) \\
\hline & GA & 0.070 & 1.000 \\
\hline & AA & 0.012 & 1.000 \\
\hline \multirow[t]{3}{*}{ TGF- $\beta$ (Codon- I0) } & Leu/Leu & (Ref) & (Ref) \\
\hline & Leu/Pro & 0.596 & 1.000 \\
\hline & Pro/Pro & 0.072 & 1.000 \\
\hline \multirow[t]{3}{*}{ TGF- $\beta$ (Codon-25) } & Arg/Arg & (Ref) & (Ref) \\
\hline & Arg/Pro & 1.000 & 1.000 \\
\hline & Pro/Pro & 1.000 & 1.000 \\
\hline
\end{tabular}

Notes: $\mathrm{P}=0.054$ and 0.408 for "SGF vs RE and "SGF vs DGF respectively for TGF- $\beta$ C-del; "Fischer exact test.

regression analysis for TGF- $\beta$ (Table 6). The haplotype frequencies of TGF- $\beta$ gene (codon-10 and 25) were comparable in RE, SGF and controls and none of the haplotypes showed any risk for rejection.

\section{Combined genotype analysis of cytokine gene polymorphisms}

IL-4 and TNF- $\alpha$ showed significant association with rejection of allograft and cytokines are reported to show synergistic effect. We, therefore evaluated the combined inter-gene interaction of IL-4 with IL-2 and IL-6, TNF- $\alpha$ -308 and TNF- $\alpha$ (-308) with TGF- $\beta$ (codon-10, 25 and C-deletion) with rejection episode taking low risk alleles combination of IL-4 (B2) with low IL-2 (G), IL-6 (C) and TNF- $\alpha-308$ while high producers of TGF- $\beta$ (C) as referent group using binary logistic regression analysis. Among different genotype combinations, IL-4 $4^{\text {high }}-I L-2^{\text {low }}$ and IL- $4^{\text {high }}$ IL- ${ }^{\text {high }}$ showed significantly a higher risk for RE (OR, 3.920; 95\%CI, 1.07-14.2; $\mathrm{p}=0.038$; OR, 3.360; 95\%CI, $1.03-10.9 ; p=0.045$, respectively) (Table 7). Significant difference was also observed for IL- $4^{\text {high }}$-TNF- $\alpha^{308 \text { high }}$ and
TNF- $\alpha^{308}$-TGF- $\beta^{\mathrm{C} \text {-del }}$ combined genotype $(\mathrm{p}=0.004$ and 0.005 ). We observed that recipients with combination of high IL-4 and high TNF- $\alpha$; TNF- $\alpha$ (high producer) and TGF- $\beta$ (low producer) are at higher risk for rejection.

\section{Discussion}

Cytokines are essential for control of immune response as most of the immunosuppressive drugs target cytokine production or their action. Inter-individual variations occur for sensitivity to different immunosuppressive drugs as manifested by either rejection or toxicity in patients with blood drug concentrations within the therapeutic range.

Cytokines have the potential to influence various immune and inflammatory responses within the graft. The difference in cytokine production between individuals is intensified in presence of human leukocyte antigen (HLA) mismatching. In our study, no significant association for DR and DQ mismatches with different cytokine genotypes for rejection was observed. Our observations complimented the findings of Capei and colleagues (2004) showing that matched grafts were lost in same proportion as the mismatched.

A significant association of high producing genotypes B1B1 of IL-4 and AA of TNF- $\alpha-308$ with the allograft rejection were observed showing a higher risk for rejection. However, genotypic frequencies did not differ significantly for other cytokine gene variants in our population. To assess the reliability we showed that recipients with B1B1 gene variant of IL-4 had $>6$-fold higher risk and AA of TNF- $\alpha-308$ showed $>7$-fold higher risk. The TGF- $\beta$ $C$-del showed a marginal significance and the frequency of low producing genotype $\mathrm{C} / \mathrm{CC}$ of TGF- $\beta$ showed 2.6-fold risk. Our findings showing higher frequency of rejection episode in recipients having high producing genotype (B1B1) of IL-4 corroborate the previous observation, which opined that $\mathrm{Th} 2$ cytokines promote both acute and chronic allograft rejection (Mhoyan et al 2003). IL-4 VNTR, intron 3 has not been previously reported in renal transplant patients. A recent study by Amirzargar and colleagues (2007) reported a significant association of IL-4 -33 gene with renal allograft outcome. Strong association of TNF- $\alpha-308$ polymorphism with rejection episode in our study are in accord with a study of Alakulppi and colleagues (2004) and Park and colleagues (2004) reporting the association of RE with AA genotype. On the contrary Dmitrienko and colleagues (2005) did not show any association of TNF- $\alpha-308$ with rejection episodes. The TNF- $\alpha-308 \mathrm{G} / \mathrm{A}$ is a promoter polymorphism and AA genotype is associated with its high production. Elahi and colleagues (2006) suggested that increased circulating levels 
Table 5 Influence of cytokines genotypes on cyclosporine trough blood levels and dose requirements at one month in stable renal allograft patients

\begin{tabular}{|c|c|c|c|}
\hline Genotype & $\begin{array}{l}\text { Allelic status }(n) \\
\text { dose requirement }\end{array}$ & (C2 level $\mu \mathrm{g} / \mathrm{ml})$ & p-value ${ }^{\dagger}$ \\
\hline IL-2 -330 & $\mathrm{T} / \mathrm{T}(49)$ & $1.56 \pm 0.13$ & \\
\hline \multirow[t]{2}{*}{ T/G } & $\mathrm{T} / \mathrm{G}(62)$ & $1.64 \pm 0.12$ & 0.012 \\
\hline & G/G (24) & $1.63 \pm 0.15$ & \\
\hline IL-4 & $\mathrm{BI} / \mathrm{BI}(3)$ & $1.60 \pm 0.14$ & \\
\hline \multirow[t]{2}{*}{ VNTR, Intron3 } & $\mathrm{BI} / \mathrm{B} 2(40)$ & $1.61 \pm 0.12$ & 0.621 \\
\hline & B2/B2 (92) & $1.64 \pm 0.12$ & \\
\hline II-6 - I74 & G/G (94) & $1.56 \pm 0.14$ & \\
\hline \multirow[t]{2}{*}{$\mathrm{G} / \mathrm{C}$} & G/C (I8) & $1.60 \pm 0.13$ & 0.363 \\
\hline & C/C (23) & $1.62 \pm 0.13$ & \\
\hline TNF- $\alpha-308$ & G/G (39) & $1.59 \pm 0.09$ & 0.209 \\
\hline \multirow[t]{2}{*}{$\mathrm{G} / \mathrm{A}$} & G/A (59) & $1.60 \pm 0.16$ & \\
\hline & $\mathrm{A} / \mathrm{A}(37)$ & $1.63 \pm 0.12$ & \\
\hline TGF- $\beta$ Codon 10 & $\mathrm{~T} / \mathrm{T}(24)$ & $1.57 \pm 0.17$ & \\
\hline \multirow[t]{2}{*}{$\mathrm{T} / \mathrm{C}$} & $\mathrm{T} / \mathrm{C}(8 \mathrm{I})$ & $1.61 \pm 0.13$ & 0.563 \\
\hline & C/C (30) & $1.63 \pm 0.12$ & \\
\hline TGF- $\beta$ Codon 25 & G/G (84) & $1.62 \pm 0.15$ & \\
\hline \multirow[t]{2}{*}{$\mathrm{G} / \mathrm{C}$} & G/C (28) & $1.56 \pm 0.12$ & 0.010 \\
\hline & $C / C(23)$ & $\mathrm{I} .62 \pm 0.07$ & \\
\hline TGF- $\beta$ C-del & $\mathrm{CC} / \mathrm{CC}(119)$ & $1.60 \pm 0.14$ & 0.544 \\
\hline C-deletion & $\mathrm{C} / \mathrm{CC}(16)$ & $\mathrm{I} .62 \pm 0.09$ & \\
\hline
\end{tabular}

Notes: Values are given as arithmetic mean $\pm \mathrm{SD} ;{ }^{*} \mathrm{P}<0.05$ ( ${ }^{\dagger}$ Kruskal-Wallis test).

of TNF- $\alpha$ in the rejecting kidneys trigger inducible nitric oxide synthase expression and damage to the microvascular endothelial cells, a characteristic feature of acute vascular rejection. Genotypic frequencies of IL-4, TNF- $\alpha-308$ and TGF- $\beta$ codon 10 differed significantly between patients and controls showing that these variations may be linked with a susceptibility to suffer from ESRD, which complimented our earlier study in ESRD patients (Manchanda et al 2006; Mittal and Manchanda 2007a, 2007b).

One of the strategies used currently to overcome rejection episode was to correlate affected cytokine gene polymorphism with immunosuppressant like cyclosporine levels, a calcineurin inhibitor used for preventing allograft rejection. Its pharmacokinetic characteristics vary greatly among individuals, and daily doses are adjusted to whole-blood cyclosporine concentration.

The role of cytokines variation in cyclosporine pharmacogenetics can be well explained by a study by Hartel and colleagues (2004) who opined the ability of immunosuppressive drugs to remove the negative regulatory signals for IL-2-like IL-10, due to inter-individual variation. Out of 7 cytokine SNPs tested, two cytokines IL-2 and

Table 6 Distribution of haplotypes of TGF- $\beta$ (codon 10 and 25) gene in controls, transplant patients, RE and SGF

\begin{tabular}{lllllll}
\hline Haplotype & $\begin{array}{l}\text { Controls } \\
(\%)\end{array}$ & $\begin{array}{l}\text { Recipients } \\
(\%)\end{array}$ & $\begin{array}{l}\text { RE } \\
(\%)\end{array}$ & $\begin{array}{l}\text { SGF } \\
(\%)\end{array}$ & $\begin{array}{l}\text { P, OR; 95\% Cl } \\
\text { (*Recipients vs } \\
\text { Controls) }\end{array}$ & $\begin{array}{l}\text { P, OR; 95\% CI } \\
\text { (*RE vs SGF) }\end{array}$ \\
\hline Leu-Arg & $88(48.9)$ & $68(37.0)$ & $16(47.1)$ & $49(36.3)$ & $1.0($ Ref) & 1.0 (Ref) \\
Pro-Arg & $54(30.0)$ & $66(35.9)$ & $10(29.4)$ & $49(36.3)$ & $0.061,1.582 ;(0.98-2.55)$ & $0.297,0.625 ;(0.25-1.51)$ \\
Pro-Pro & $15(8.3)$ & $19(10.3)$ & $1(2.9)$ & $14(10.4)$ & $0.195,1.639 ;(0.77-3.46)$ & $0.157,0.219 ;(0-0)$ \\
Leu-Pro & $23(12.8)$ & $31(16.8)$ & $7(20.6)$ & $23(17.0)$ & $0.081,1.744 ;(0.93-3.26)$ & $0.892,0.932 ;(0.33-2.57)$ \\
\hline
\end{tabular}

Note: "Binary Logistic regression analysis. 
Table 7 Allograft rejection risk for combined effect of cytokine gene polymorphisms between SGF and RE

\begin{tabular}{|c|c|c|c|}
\hline Combined genotype & RE (n = 34); (\%) & SGF $(n=135) ;(\%)$ & ${ }^{*} \mathrm{OR}$ at $95 \% \mathrm{Cl}$; p-value \\
\hline IL-4 ${ }^{\text {high }}-I L-2^{\text {low }}$ & $7(20.6)$ & $15(11.1)$ & 3.920 (I.07-14.2); 0.038 \\
\hline IL-4 $4^{\text {high-IL-- }}{ }^{\text {high }}$ & $10(29.4)$ & $25(18.5)$ & 3.360 (I.03-10.9); 0.045 \\
\hline IL-4 low_IL-2 ${ }^{\text {high }}$ & $12(35.3)$ & $53(39.3)$ & $1.902(0.62-5.8) ; 0.260$ \\
\hline 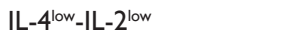 & $5(14.7)$ & $42(31.1)$ & I.00 (Reference) \\
\hline IL-4 ${ }^{\text {high }}-I L-6^{\text {low }}$ & $3(8.8)$ & II (8.I) & $1.052(0.22-4.82) ; 0.948$ \\
\hline IL-4 ${ }^{\text {high-IL-6 }}{ }^{\text {high }}$ & $13(38.2)$ & $31(23.0)$ & $1.618(0.56-4.6) ; 0.371$ \\
\hline IL-4 low_IL-6 high $^{\text {hish }}$ & II (32.3) & $66(48.9)$ & $0.643(0.22-1.83) ; 0.409$ \\
\hline IL-4 $4^{\text {low_IL-6 low }}$ & $7(20.6)$ & $27(20.0)$ & I.00 (Reference) \\
\hline IL-4 ${ }^{\text {high }}-T N F-\alpha^{308 / l o w}$ & $3(8.8)$ & $6(4.4)$ & $2.149(0.43-10.52) ; 0.345$ \\
\hline IL-4high_TNF- $\alpha^{308 / h i g h}$ & $18(53.0)$ & $32(23.7)$ & $9.600(2.05-44.93) ; 0.004$ \\
\hline IL-4 $4^{\text {low-TNF- }} \alpha^{308 / \text { high }}$ & $10(29.4)$ & $65(48.2)$ & $8.000(I .09-58.54) ; 0.04 I$ \\
\hline IL-4low-TNF- $\alpha^{308 / \text { low }}$ & $3(8.8)$ & $32(23.7)$ & I.00 (Reference) \\
\hline TNF- $\alpha^{308 / \text { low_TGF- } \beta^{10 / \text { high }}}$ & I (2.9) & $10(7.4)$ & I.00 (Reference) \\
\hline TNF- $\alpha^{308 / \text { high }}-T G F-\beta^{10 / l o w}$ & $29(85.3)$ & $82(60.7)$ & 3.537 (0.43-28.84); 0.238 \\
\hline TNF- $\alpha^{308 / \text { high }-T G F-~} \beta^{10 / \text { high }}$ & $2(5.9)$ & $14(10.4)$ & $1.429(0.11-18.00) ; 0.783$ \\
\hline 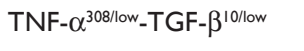 & $2(5.9)$ & $29(21.5)$ & $0.690(-) ; 0.771$ \\
\hline TNF- $\alpha^{308 / l o w}-T G F-\beta^{25 / \text { high }}$ & I (2.9) & $27(20.0)$ & 1.00 (Reference) \\
\hline TNF- $\alpha^{308 / \text { high }-T G F-~} \beta^{25 \text { low }}$ & $10(29.4)$ & 39 (28.9) & $6.923(0.83-57.29) ; 0.073$ \\
\hline TNF- $\alpha^{308 / \text { high }}-$ TGF- $-\beta^{25 / h i g h}$ & $21(61.8)$ & $57(42.2)$ & $0.029,9.947(1.27-77.86)$ \\
\hline TNF- $\alpha^{308 / l o w}-T G F-\beta^{25 / l o w}$ & $2(5.9)$ & $12(8.9)$ & $0.237,4.500(0.37-54.54)$ \\
\hline TNF- $\alpha^{308 / l o w}-T G F-\beta^{C-d e l / h i g h ~}$ & $2(5.9)$ & $35(25.9)$ & 1.00 (Reference) \\
\hline TNF- $\alpha^{308 / h i g h-T G F-~} \beta^{\text {C-dellow }}$ & $9(26.5)$ & $12(8.9)$ & $0.002,13.125(2.47-69.48)$ \\
\hline TNF- $\alpha^{308 / h i g h}-T G F-\beta^{C-d e / / h i g h}$ & $23(67.6)$ & $84(62.2)$ & $0.040,4.792(1.07-21.42)$ \\
\hline TNF- $\alpha^{308 / l o w}-T G F-\beta^{\text {C-del/low }}$ & $0(0.0)$ & $4(3.0)$ & - \\
\hline
\end{tabular}

Note: "Binary logistic regression analysis.

TGF- $\beta$ codon 25 SNP were significantly associated with dose-adjusted C2 level showing that C2 level was lower or possibly better absorption of cyclosporine in patients with TT genotype of IL-2 and heterozygous GC of TGF- $\beta$. This is perhaps a first report from north Indian population showing a significant association of cytokine gene variants with cyclosporine dose requirement.

Cytokines illustrate synergistic effect if the combined effect of two cytokines on cellular activity is greater than the additive effects of individual cytokine. A combined analysis of the effect of IL-4 in combination with IL-2 showed significant risk with both low and high IL-2 genotypes. Another combination of high IL-4 with high TNF- $\alpha$ demonstrated a significant higher risk for rejection. This observation suggested that IL-4 cytokine could have synergistic effect with TNF-A reflecting gene-gene interaction. The other combination of TNF- $\alpha(-308)$ with TGF-B projecting recipients with TNF- $\alpha^{308 / \text { high }}$-TGF- $\beta^{\text {C-del/low }}$ associated with higher risk of rejection. Our observations suggested that high producing genotypes of proinflammatory cytokine TNF- $\alpha$ and low producing genotypes of TGF- $\beta$ (anti-inflammatory) may have a major impact on the immune response responsible for allograft acceptance/rejection (Park et al 2004).

IL-2 did not show any significant association with the rejection in our population, which is in agreement to the study of Poli and colleagues (2001) and Pawlik and colleagues (2005a) showing no association of IL-2 -330 with acute rejection after kidney transplantation. The reason behind no association of IL-2 could be that patients are given high therapeutic doses of CsA during the early period of transplantation. It is plausible that a standard high dose of CsA may be adequate for the complete blockage of IL-2 production in individuals that carry high producer IL-2 genotype thus leading to better graft survival. It is known that under conditions of 
allo-stimulation and immunosuppression, the influence of the $\mathrm{T} / \mathrm{T}$ and $\mathrm{T} / \mathrm{G}$ genotypes on IL-2 production could be different from that observed in vitro (Morgun et al 2003).

IL-6 polymorphism did not reflect any association in our population. Our findings are in agreement with Poli and colleagues (2001) and Lacha and colleagues (2005) showing no association of IL-6 with rejection. On the contrary Pawlik and colleagues (2005b) demonstrated IL-6 CC genotype to be associated with an increased risk of rejection. Contradiction in results perhaps could be best resolved by functional studies that may be required to provide new insights into the role of IL- 6 .

TGF- $\beta$ is a pleiotropic cytokine with unique and potent anti-inflammatory and there are several reports showing the protective roles of TGF- $\beta$ (Ma et al 2004; Wang et al 2005). Analysis of TGF- $\beta$ C-del, codon-10 and 25 revealed that low producing genotype $\mathrm{C} / \mathrm{CC}$ of $\mathrm{C}-\mathrm{del}$ and 'Pro-Pro' of codon-10 was significantly associated with higher risk for rejection which complimented the study by Park and colleagues (2004).

Delayed graft function is linked to several long-term risks for acute rejection subsequently leading to allograft dysfunction and graft loss. A number of clinical factors may be linked with DGF. We did not detect significant difference in cytokine gene variants in patients of SGF and DGF, which could be related to the small number of patients studied. Our findings corroborate with the studies of Alakulppi and colleagues (2004) and Pawlik and colleagues (2005b) who in their study too, reported no association of different cytokines gene studied with delayed graft functioning.

Due to an high degree of LD observed between SNPs of TGF- $\beta$ codon 10 and 25 , disease variants may be revealed through evaluation of underlying haplotypes. Hence we constructed haplotypes for TGF- $\beta$ polymorphism in our study. TGF- $\beta$ gene (codon-10 and 25) haplotype frequencies were comparable in RE, SGF and controls. Haplotypic frequency of TGF-B in our population matched with the Caucasians (Coll et al 2004).

The sample size, though low, may be a limitation due to single centre, nevertheless, the results obtained from this present study constituted a preliminary step and initial understanding of the role of cytokine gene polymophism in renal transplant. Hence, further analyses in large multicenter allograft series are warranted.

\section{Conclusion}

Strong associations of high producing genotypes B1B1 of IL-4 and AA of TNF- $\alpha-308$ while low producing genotype
Pro/Pro of TGF- $\beta$ codon-10 in our population substantiate that both Th1 and Th2 derived cytokines could be an important risk factor for kidney transplant rejection. High producing genotype TT of IL- 2 and heterozygous GC of TGF- $\beta$ codon 25 polymorphism were highly associated with cyclosporine dose requirements in stable renal transplant patients suggesting that recipients may require higher dose with these genotypes. Combined genotype analysis of gene-gene interaction demonstrated synergistic effect of TNF- $\alpha$ with IL-4 and TGF- $\beta$ increasing the risk for rejection. Our study further suggests that pre-transplantation assessment of this variability could be a powerful tool for better choice of immunosuppressive agents for optimization of individual immunosuppressive therapy. Given the importance of rapidly achieving target blood concentrations after transplantation, further prospective studies should consider the immediate post-graft period and assess the influence of specific polymorphism.

\section{Acknowledgements}

This study was funded by intramural grant of the Institute provided to RDM. Ms. PK. Manchanda is thankful to Council of Scientific and Industrial Research New Delhi for awarding senior research fellowship (SRF). The authors report no conflicts of interest in this work.

\section{References}

Alakulppi NS, Kyllonen L, Jantti VT, et al. 2004. Cytokine gene polymorphisms and risks of acute rejection and delayed graft function after kidney transplantation. Transplantation, 78:1422-8.

Amirzargar M, Yavangi M, Basiri A, et al. 2007. Genetic association of interleukin-4, interleukin-10, and transforming growth factor-beta gene polymorphism with allograft function in renal transplant patients. Transplant Proc, 39:954-7.

Coll E, Cormand B, Campos B, et al. 2004. Association of TGF-beta1 polymorphisms with chronic renal disease. J Nephrol, 17:794-9.

Cox ED, Hoffmann SC, DiMercurio BS, et al. 2001. Cytokine polymorphic analyses indicate ethnic differences in the allelic distribution of interleukin-2 and interleukin-6. Transplantation, 72:720-6.

Dmitrienko S, Hoar DI, Balshaw R, et al. 2005. Immune response gene polymorphisms in renal transplant recipients. Transplantation, 80:1773-82.

Elahi MM, Matata BM, Hakim NS. 2006. Quiescent interplay between inducible nitric oxide synthase and tumor necrosis factor-alpha: influence on transplant graft vasculopathy in renal allograft dysfunction. Exp Clin Transplant, 4:445-50.

Gendzekhadze K, Rivas-Vetencourt P, Montano RF. 2006. Risk of adverse post-transplant events after kidney allograft transplantation as predicted by CTLA- $4+49$ and TNF-alpha -308 single nucleotide polymorphisms: a preliminary study. Transpl Immunol, 16:194-9.

Gyan BA, Goka B, Cvetkovic JT, et al. 2004. Allelic polymorphisms in the repeat and promoter regions of the interleukin- 4 gene and malaria severity in Ghanaian children. Clinical and Experimental Immunology, 138:145-50.

Hartel C, Schumacher N, Fricke L, et al. 2004. Sensitivity of wholeblood T lymphocytes in individual patients to tacrolimus (FK 506): impact of interleukin-2 mRNA expression as surrogate measure of immunosuppressive effect. Clin Chem, 50:141-51. 
Hutchinson IV, Pravica V, Perrey C, et al. 1999. Cytokine gene polymorphisms and relevance to forms of rejection. Transplant proc, 31:734-6.

Khan F, Agrawal S, Agrawal S. 2006. Genetic predisposition and renal allograft failure implication of non-HLA genetic variants. Mol Diag Ther, 10:205-19.

Koo SH, Lee EJ. 2006. Pharmacogenetics approach to therapeutics. Clin Exp Pharmacol Physiol, 33:525-32.

Lacha J, Hribova P, Kotsch K, et al. 2005. Effect of cytokines and chemokines (TGF-beta, TNF-alpha, IL-6, IL-10, MCP-1, RANTES) gene polymorphisms in kidney recipients on posttransplantation outcome: influence of donor-recipient match. Transplant Proc, 37:764-6.

Loucaidou M, Stitchbury J, Lee J, et al. 2005. Cytokine polymorphisms do not influence acute rejection in renal transplantation under tacrolimus-based immunosuppression. Transplantation Proc, 37:1760-1.

Ma LJ, Jha S, Ling H, et al. 2004. Divergent effects of low versus high dose anti-TGF-beta antibody in puromycin aminonucleoside nephropathy in rats. Kidney Int, 65:106-15.

Manchanda PK, Kumar A, Kaul A, et al. 2006. Correlation between a gene polymorphism of tumor necrosis factor-alpha (G/A) and end-stage renal disease: a pilot study from north India. Clin Chim Acta, 370:152-7.

Marshall SE, McLaren AJ, Haldar NA, et al. 2000. The impact of recipient cytokine genotype on acute rejection after renal transplantation. Transplantation, 70:1485-91.

Mas V, Maluf D, Archer K, et al. 2007. Establishing the molecular pathways involved in chronic allograft nephropathy for testing new noninvasive diagnostic markers. Transplantation, 83:448-57.

McDaniel DO, Barber WH, Nguyan C, et al. 2003. Combined analysis of cytokine genotype polymorphism and the level of expression with allograft function in African-American renal transplant patients. Transpl Immunol, 11:107-19.

Mhoyan A, Wu GD, Kakoulidis TP, et al. 2003. Predominant expression of the Th2 response in chronic cardiac allograft rejection. Transplant Int, 16:464-73.

Miller SA, Dykes DD, Polesky HF. 1988. A simple salting out procedure for extracting DNA from human nucleated cells. Nucleic Acids Res, 16:1215-5.

Mittal RD, Manchanda PK. 2007a. Association of interleukin (IL)-4 intron-3 and IL-6 -174 G/C gene polymorphism with susceptibility to end-stage renal disease. Immunogenetics, 59:159-65.

Mittal RD, Manchanda PK. 2007b. Is low frequency distribution of TGF- $\beta$ genotype associated with increased risk for end stage renal disease? DNA Cell Biol, 26:172-7.
Morgun A, Shulzhenko N, Rampim GF, et al. 2003. Interleukin-2 gene polymorphism is associated with renal but not cardiac transplant outcome. Transplant Proc, 35:1344-5.

Myers BD, Newton L. 1991. Cyclosporine-induced chronic nephropathy: an obliterative microvascular renal injury. J Am Soc Nephrol, 2(Suppl 1):S45.

Park JY, Park MH, Park H, et al. 2004. TNF-alpha and TGF-beta1 gene polymorphisms and renal allograft rejection in Koreans. Tissue Antigens, 64:660-6.

Pawlik A, Domanski L, Rozanski J, et al. 2005a. IL-2 and TNF-alpha promoter polymorphisms in patients with acute kidney graft rejection. Transplant Proc, 37:2041-3.

Pawlik A, Domanski L, Rozanski J, et al. 2005b. The cytokine gene polymorphisms in patients with chronic kidney graft rejection. Transpl Immunol, 14:49-52.

Perrey C, Turner SJ, Pravica V, et al. 1999. ARMS-PCR methodologies to determine IL-10, TNF-alpha, TNF-beta and TGF-beta 1 gene polymorphisms. Transpl Immunol, 7:127-8.

Pociot F, Hansen PM, Karlsen AE, et al. 1998. TGF-betal gene mutations in insulin-dependent diabetes mellitus and diabetic nephropathy. $\mathrm{J} \mathrm{Am}$ Soc Nephrol, 9:2302-7.

Poli F, Boschiero L, Giannoni F, et al. 2001. TNF alpha IFNgamma, IL-6, IL-10, and TGF-beta1 gene polymorphisms in renal allografts. Transplant Proc, 33:348-9.

Poole KL, Gibbs PJ, Evans PR, et al. 2001. Influence of patient and donor cytokine genotypes on renal allograft rejection: evidence from a single centre study. Transpl Immunol, 8:259-65.

Racusen LC, Solez K, Colvin RB, et al. 1999. The Banff 97 working classification of renal allograft pathology. Kidney Int, 55:713-23.

Sankaran D, Asderakis A, Ashraf S, et al. 1999. Cytokine gene polymorphisms predict acute graft rejection following renal transplantation. Kidney Int, 56:281-8

Skorpil N, Kolesar L, Striz I, et al. 2007. Cytokine gene polymorphisms in the Dutch population. Int J Immunogenet, 34:87-90.

Tan D, Wu X, Hou M, et al. 2005. Interleukin-6 polymorphism is associated with more aggressive prostate cancer. J Urol, 174:753-6.

Tsai FJ, Lu HF, Yeh LS, et al. 2001. Lack of evidence for the association of tumor necrosis factor-alpha gene promoter polymorphism with calcium oxalate stone and bladder cancer patients. Urol Res, 29:412-6.

Uboldi de Capei M, Dametto E, Fasano ME, et al. 2004. Cytokines and chronic rejection: a study in kidney transplant long-term survivors. Transplantation, 77:548-2.

Wang W, Huang XR, Li AG, et al. 2005. Signaling mechanism of TGF-beta1 in prevention of renal inflammation: role of Smad7. Am Soc Nephrol, 16:1371-83. 